\title{
Financial hardship associated with colorectal cancer survivorship: The role of asset depletion and debt accumulation
}

\author{
Paul Hanly ${ }^{1}$ (D) । Rebecca Maguire ${ }^{2}$ (D) । Alan O Ceilleachair ${ }^{3}$ । Linda Sharp ${ }^{4}$ (1)
}

${ }^{1}$ National College of Ireland, Dublin, Ireland

${ }^{2}$ Maynooth University, Maynooth, Ireland

${ }^{3}$ National Cancer Registry, Cork, Ireland

${ }^{4}$ Newcastle University, Newcastle upon Tyne, UK

Correspondence

Paul Hanly, National College of Ireland, Mayor Street, Dublin 1, Ireland.

Email: paul.hanly@ncirl.ie

Funding information

Irish Health Research Board, Grant/Award

Number: SA/2004/1

\begin{abstract}
Objective: To estimate the prevalence of financial objective stress and subjective strain among colorectal cancer survivors and assess associated financial coping factors in Ireland, which has a mixed public-private health care system.
\end{abstract}

Methods: Colorectal cancer survivors were identified from the National Cancer Registry, and a sample of 496 respondents were included in the analysis. A postal survey collected information on survivor demographics, socio-economic background, medical characteristics, cancer-related financial hardship, debt accumulation, and asset depletion. Cancer-related financial objective stress and subjective strain were used as dependent variables in logistic regression analysis.

Results: Approximately 2 in 5 survivors experienced objective stress $(40.9 \%)$ or subjective strain (39.4\%). Depletion of savings (49.1\%) was the most prevalent form of financial coping strategy. Factors significantly associated with increased objective stress were having a stoma $(\mathrm{OR}=2.1 ; 95 \% \mathrm{Cl}, 1.1-3.9)$, using savings $(\mathrm{OR}=9.4$; $95 \% \mathrm{Cl}$, 4.9-18.0), formally borrowing money ( $\mathrm{OR}=3.1 ; 95 \% \mathrm{Cl}, 1.0-9.6)$, and loans from family members/friends $(\mathrm{OR}=3.8 ; 95 \% \mathrm{Cl}, 1.9-7.8)$. Not working (excluding retirees) $(\mathrm{OR}=0.44 ; 95 \% \mathrm{Cl}, 0.20-0.96)$ was associated with decreased objective stress. Significant predictors of subjective strain included having dependents, a stoma, using savings ( $\mathrm{OR}=5.3 ; 95 \% \mathrm{Cl}, 2.9-9.5)$, and loans from family members/friends $(\mathrm{OR}=2.0 ; 95 \% \mathrm{Cl}, 1.1-3.9)$ but excluded borrowing money.

Conclusions: Cancer-related financial objective stress and subjective strain are common in colorectal cancer survivors, even where all citizens are entitled to publicly funded care, but the financial coping strategies significantly associated with these 2 measures differed. These findings will help inform targeted measures across disparate health care systems and survivor groups to alleviate financial hardship.

\section{KEYWORDS}

cancer, colorectal, financial stress, financial support, logistic model, oncology, psychological strain

\section{BACKGROUND}

The financial consequences of a cancer diagnosis for patients/survivors are disparate in nature. They often incur medical (eg, treatment co-payments) and nonmedical (eg, transportation, parking, and home improvements) out-of-pocket costs. ${ }^{1}$ Cancer survivors working at the time of diagnosis may have to take extended leave from employment, return to work on reduced hours, or retire prematurely. ${ }^{2}$

Recent studies reveal survivors falling into debt because of their treatment, ${ }^{3}$ being forced to borrow money or using up savings to pay for medical bills, ${ }^{4-7}$ selling their property, and even filing for bankruptcy. ${ }^{4,8,9}$ These cost-coping strategies can lead to difficult trade-offs 
between spending on basic needs and spending on cancer-related health care $^{3}$ which in turn can lead to survivors delaying or discontinuing cancer treatment. ${ }^{10,11}$

Colorectal cancer is the third most commonly diagnosed cancer globally. ${ }^{12}$ Evidence exits that colorectal cancer patients incur outof-pocket costs even in publicly funded health systems. ${ }^{1}$ However, relatively little is known of the specific financial coping strategies of survivors. The few available studies focus on colorectal cancer survivors in the United States with a primarily private health care system. Little evidence is available of experiences in mixed health care settings.

Another limitation of the literature is that it has tended not to distinguish between cancer-related financial objective stress and subjective strain. Composite measures of financial hardship do not distinguish between hardship related to available financial resources and how the patient feels about their lack of financial resources. ${ }^{3}$ The distinction is important. Objective stress related to cancer can hinder health care access and the quality and intensity of care, while subjective strain is more associated with emotional strain and the engagement of patients with existing medical care supports. ${ }^{13}$ Consequently, both measures should be considered in providing a broader perspective of the financial burden of cancer. ${ }^{14,15}$

Our study aims to estimate the prevalence of both financial objective stress and subjective strain among colorectal cancer survivors in Ireland, a high-income country with a mixed public-private health care system, and to assess the factors associated with hardship, specifically focusing on survivor asset depletion and debt accumulation.

\section{2 | METHODS}

\section{1 | Ethical statement}

Ethical approval was obtained from research ethics committees covering participants' treating hospitals. These included large tertiary centres of excellence, regional and local hospitals. Written informed consent was obtained from all individual participants.

\section{2 | Setting}

Ireland has a mixed public-private health care system. Medical cardholders are entitled to free inpatient hospital care, free GP consultations, and prescription medicine capped at $€ 25$ per month. Currently, medical cards are means tested in those aged $<70$ (threshold of $€ 500$ per week for a single person and $€ 900$ per week for couples), while those aged 70+ are automatically entitled to one. Nonmedical cardholders pay for GP consultations (approximately $€ 60$ per visit) and make co-payments for inpatient public hospital care (€80 per day), in addition to a maximum cap on out-of-pocket payment for prescription medication of $€ 134$ per month per person). Approximately half the population hold private health insurance. ${ }^{16}$

\section{3 | Subjects}

Eligible participants were sampled from the population-based National Cancer Registry Ireland. The sample consisted of all cases of primary invasive colorectal cancer in Ireland (ICD10: C18-C20) diagnosed October 2007 to September 2009 and still alive in January 2010. Inclusion criteria comprised knowledge of their cancer diagnosis, an understanding of English, and being healthy enough to participate (including no cognitive impairment). Recruitment involved treating clinicians screening their patient lists for potential eligibility. We sent a questionnaire to 1273 colorectal cancer survivors between April and September 2010, with up to 2 reminder letters sent 2 and 4 weeks after to nonresponders.

\section{4 | Measures and data collection}

The survey contained questions on the economic and financial consequences of a colorectal cancer diagnosis. Questionnaire content was informed by literature review, interviews with colorectal cancer survivors, and focus group discussions with colorectal cancer patient support groups. ${ }^{17}$

\subsection{1 | Measures of objective and subjective finan- cial burden}

We followed previous research ${ }^{13,18-20}$ to assess cancer-related financial objective stress and subjective strain. Objective stress was assessed by asking respondents "has your cancer diagnosis made your household's ability to make ends meet?" and providing 7 potential responses ranging from "much more difficult" to "much less difficult." Subjective strain was assessed by asking "since your cancer diagnosis, how have you felt about your household's financial situation?" and providing 7 potential responses ranging from "much more concerned" to "much less concerned." Both sets of responses were transformed for analysis into dichotomous variables. Participants who responded with more difficult (much more, more, and a little more) or more concerned (much more, more, and a little more) were considered to have experienced objective stress and subjective strain, respectively, and their responses were recoded as 1 with the remaining responses recoded as 0 . Both questions have been used previously ${ }^{18-20}$ and have shown convergent and face validity.

\subsection{2 | Survivor financial debt accumulation and asset depletion}

Respondents were asked whether they had savings at the time of their diagnosis, and if so, whether none, some, or all these savings were used because of their diagnosis. A categorical variable with 3 levels was created: "no savings," "had savings but not used," and "had savings and used." Measures of respondent borrowing from formal lending institutions and/or informal loans from family members or friends because of a diagnosis were collected on a yes/no basis and were included as dichotomous variables.

\subsection{3 | Additional covariates}

Three groups of variables known from the literature $3,21,22$ to impact on financial hardship among cancer survivors were sourced from the study survey and the National Cancer Registry. Demographic variables were age at questionnaire completion, gender, marital status, whether the respondent had children, whether the respondent had dependents, and whether the respondent lived alone. Socio-economic 
variables were highest level of education, employment status at time of diagnosis, whether the respondent was in receipt of social welfare payments at the time of diagnosis, whether the respondent possessed a medical card (either immediately prior to the diagnosis or subsequently obtained), and whether the respondent possessed private health insurance. Clinical variables were cancer site (colon/rectal), stage at diagnosis, treatment received (surgery, chemotherapy, and radiotherapy) within a year of diagnosis, and presence of a stoma between treatment and time of questionnaire completion.

\section{5 | Statistical analysis}

Two hierarchical binary logistic regression models were used to estimate the association between covariates and cancer-related financial objective stress and subjective strain. Each model contained 2 blocks of covariates. In block 1, known demographic, socio-economic, and clinical covariates from the literature were included in the model simultaneously if they were statistically significant in univariate analyses (likelihood ratio tests: $P<.05$ ). Block 2 of the hierarchical model included financial debt accumulation and asset depletion covariates. A likelihood ratio test was conducted to determine the overall contribution of these debt and asset depletion covariates to the models. The factors in the final models had low variance inflation factors and high tolerances. The models also showed adequate goodness of fit.

\section{3 | RESULTS}

\section{1 | Response rate and respondent characteristics}

Four hundred and ninety-seven completed questionnaires were returned (response rate $=39 \%$ ); however, one respondent was excluded because of incompleteness of responses. Table 1 shows respondent characteristics. Respondents were 1.8 years post diagnosis on average at the time of questionnaire completion.

Respondents and nonrespondents were compared across a range of variables to investigate potential nonresponse bias. Nonresponders did not differ by sex or cancer site; however, they did differ by age group at diagnosis (nonresponders were slightly older [mean age 67 vs $70 ; P<.001$ ] than responders), but age was not a significant predictor of objective stress or subjective strain.

\section{2 | Prevalence of financial objective stress and subjective strain}

A total of $40.9 \%$ survivors reported cancer-related financial objective stress post diagnosis, compared with $53.4 \%$ who reported it was neither more nor less difficult and $2.2 \%$ who reported less difficulty making ends meet. Slightly fewer (39.4\%) reported cancer-related financial subjective strain post diagnosis indicating more concern about their household financial situation, compared with $48.5 \%$ who indicated no more or less concerned and $12.1 \%$ who reported less concern (a summary of responses is presented in Figure S1).
TABLE 1 Colorectal cancer survivors' characteristics

\begin{tabular}{|c|c|c|}
\hline Characteristics & Number & Valid \% \\
\hline \multicolumn{3}{|l|}{ Demographics } \\
\hline \multicolumn{3}{|l|}{ Gender } \\
\hline Male & 310 & 62.5 \\
\hline Female & 186 & 37.5 \\
\hline \multicolumn{3}{|l|}{ Age } \\
\hline$<65$ & 199 & 40.1 \\
\hline $65-74$ & 167 & 33.7 \\
\hline $75+$ & 130 & 26.2 \\
\hline \multicolumn{3}{|l|}{ Marital status } \\
\hline Married/cohabiting & 369 & 75.6 \\
\hline Other & 119 & 24.4 \\
\hline \multicolumn{3}{|l|}{ Dependents } \\
\hline No & 294 & 61 \\
\hline One or more & 188 & 39 \\
\hline \multicolumn{3}{|l|}{ Children } \\
\hline No & 65 & 13.3 \\
\hline Yes & 423 & 86.7 \\
\hline \multicolumn{3}{|l|}{ Socio-economic } \\
\hline \multicolumn{3}{|l|}{ Education } \\
\hline Primary & 149 & 30.5 \\
\hline Secondary & 230 & 47.1 \\
\hline Tertiary & 109 & 22.4 \\
\hline \multicolumn{3}{|l|}{ Employment } \\
\hline Employed & 184 & 38.4 \\
\hline Retired & 200 & 41.8 \\
\hline Not working ${ }^{a}$ & 95 & 19.8 \\
\hline \multicolumn{3}{|c|}{ In receipt of welfare payment } \\
\hline Yes & 234 & 85.4 \\
\hline No & 40 & 14.6 \\
\hline \multicolumn{3}{|l|}{ Medical } \\
\hline \multicolumn{3}{|l|}{ Stoma } \\
\hline Never had & 371 & 77.9 \\
\hline Had/has a stoma & 105 & 22.1 \\
\hline \multicolumn{3}{|l|}{ Medical card } \\
\hline No & 242 & 48.8 \\
\hline Yes & 254 & 51.2 \\
\hline \multicolumn{3}{|l|}{ Private health insurance } \\
\hline No & 240 & 48.4 \\
\hline Yes & 256 & 51.6 \\
\hline \multicolumn{3}{|l|}{ Site } \\
\hline Rectum & 189 & 38.1 \\
\hline Colon & 307 & 61.9 \\
\hline \multicolumn{3}{|l|}{ Stage } \\
\hline Stage 1 & 90 & 20.4 \\
\hline Stage 2 & 414 & 31.9 \\
\hline Stage 3 & 175 & 39.6 \\
\hline Stage 4 & 36 & 8.1 \\
\hline \multicolumn{3}{|l|}{ Surgery } \\
\hline No & 68 & 13.7 \\
\hline Yes & 427 & 86.3 \\
\hline
\end{tabular}


TABLE 1 (Continued)

\begin{tabular}{lcc} 
Characteristics & Number & Valid \% \\
Chemotherapy & 356 & 71.9 \\
No & 139 & 28.1 \\
Yes & & \\
Radiotherapy & 414 & 83.6 \\
No & 81 & 16.4 \\
Yes & 1.8 years on average \\
\hline Time since diagnosis &
\end{tabular}

a"Not working" category includes those looking after the family/home and students.

\section{3 | Prevalence of debt accumulation and asset depletion}

Tables S1 and S2 summarise the financial coping strategies of survivors following diagnosis. Overall, $30 \%$ of respondents had no savings at the time of diagnosis. Of those that did, almost a half used some $(44.8 \%)$ or all $(4.3 \%)$ of them, indicating that savings depletion was the most prevalent form of financial coping strategy. Smaller percentages of survivors reported borrowing from a financial institution (7.0\%) or seeking financial aid from a friend/family member (15.9\%).

\section{4 | Cancer-related financial objective stress multivariable model}

Following univariate analysis, a block of significantly associated demographic, socio-economic, and clinical variables was included in the multivariate model (block 1). A second block of financial coping covariates was added. The overall model (Table 2 ) was statistically significant $(P<.001)$

Having a stoma, employment status immediately before cancer diagnosis, using savings, borrowing money, and obtaining loans from family members or friends were significantly associated with cancerrelated financial objective stress. Specifically, survivors with a stoma were more than twice as likely as those without to experience objective stress $(\mathrm{OR}=2.1 ; 95 \% \mathrm{Cl}, 1.1-3.9)$. The odds of objective stress were over $50 \%$ lower $(\mathrm{OR}=0.44 ; 95 \% \mathrm{Cl}, 0.20-0.96)$ for those who were not working at the time of diagnosis (including those looking after the family/home and students) compared with those who were working. Those who borrowed money from a financial institution, or who obtained financial help from family members or friends, were between $3(\mathrm{OR}=3.1 ; 95 \% \mathrm{Cl}, 1.0-9.6)$ and 4 times $(\mathrm{OR}=3.8 ; 95 \%$ $\mathrm{Cl}, 1.9-7.8)$ more likely to experience objective stress following diagnosis compared with no borrowing or no financial help. Compared with survivors who had savings but did not use them, those who had savings and used them had almost 10 -fold raised odds of objective stress $(\mathrm{OR}=9.4 ; 95 \% \mathrm{Cl}, 4.9-18.0)$.

\section{5 | Cancer-related financial subjective strain multivariable model}

Following univariate analysis, a block of significantly associated demographic, socio-economic, and clinical variables was included in the multivariate model (block 1). A second block of financial coping covariates was added. The overall model (Table 3 ) was statistically significant $(P<.001)$.
TABLE 2 Variables significantly associated with cancer-related financial stress: Multivariate odds ratios (OR) with $95 \%$ confidence intervals and $P$ values ${ }^{a}$

\begin{tabular}{|c|c|c|c|c|}
\hline & OR & $P$ & \multicolumn{2}{|c|}{$95 \% \mathrm{Cl}$} \\
\hline \multicolumn{5}{|l|}{ Block 1 significant predictors } \\
\hline \multicolumn{5}{|c|}{ Employment status at diagnosis } \\
\hline Employed/self employed & 1 & & & \\
\hline Retired & 0.53 & .099 & 0.25 & 1.13 \\
\hline Not working ${ }^{\mathrm{b}}$ & 0.44 & .038 & 0.20 & 0.96 \\
\hline \multicolumn{5}{|l|}{ Stoma } \\
\hline No & 1 & & & \\
\hline Yes & 2.10 & .020 & 1.13 & 3.92 \\
\hline \multicolumn{5}{|c|}{$C \& S^{c} R^{2}=.143$ and $N^{d} R^{2}=.193$} \\
\hline \multicolumn{5}{|c|}{ Block 2 significant predictors } \\
\hline \multicolumn{5}{|l|}{ Formal borrowing } \\
\hline No & 1 & & & \\
\hline Yes & 3.11 & .049 & 1.01 & 9.62 \\
\hline \multicolumn{5}{|l|}{ Family/friends financial help } \\
\hline No & 1 & & & \\
\hline Yes & 3.80 & .000 & 1.86 & 7.77 \\
\hline \multicolumn{5}{|l|}{ Savings } \\
\hline Yes, not used & 1 & & & \\
\hline No & 4.82 & .000 & 2.39 & 9.68 \\
\hline Yes, and used & 9.38 & .000 & 4.87 & 18.04 \\
\hline $\begin{array}{l}C \& S R^{2} \text { change }=.165 \text { and } \\
N R^{2} \text { change }=.223\end{array}$ & & & & \\
\hline
\end{tabular}

a Model is adjusted for age at diagnosis, having dependents, having private health insurance, having a medical card, and site of cancer diagnosis, which were not significant in multivariate analysis. Overall model Cox and Snell $R^{2}$ : .308; Nagelkerke $R^{2}$ : .416; Hosmer and Lemeshow test: .718; overall model significance: $P=<.001$.

b"Not working" category includes those looking after the family/home and students.

${ }^{\mathrm{C}} \mathrm{Cox}$ and Snell.

${ }^{\mathrm{d}}$ Nagelkerke.

Having dependents, having a stoma, obtaining financial help from family members and friends, and using savings because of cancer were all significantly associated with cancer-related financial subjective strain. Specifically, those with dependents had 2.3 times higher odds (95\% Cl, 1.4-3.8) of experiencing subjective strain following diagnosis. Similarly increased odds were associated with those who had a stoma $(\mathrm{OR}=2.1 ; 95 \% \mathrm{Cl}, 1.2-3.7)$. Those obtaining financial help from family members and friends were 2 times more likely to experience subjective strain $(\mathrm{OR}=2.0 ; 95 \% \mathrm{Cl}, 1.1-3.9)$, while the use of savings was associated with 5.3 -fold increased odds of subjective strain $(95 \% \mathrm{Cl}$, 2.9-9.5).

\section{4 | DISCUSSION}

\section{1 | Debt accumulation and asset depletion}

Over half of colorectal cancer survivors used one or more financial coping strategies directly associated with their cancer diagnosis. The potential adverse impacts of this in terms of health-related quality of 
TABLE 3 Results of variables significantly associated with financial strain: Multivariate odds ratio with $95 \%$ confidence intervals and $P$ values $^{\mathrm{a}}$

\begin{tabular}{lllll} 
& OR & $P$ & $95 \% \mathrm{Cl}$ & \\
Block 1 significant predictors & & & & \\
Stoma & & & & \\
$\quad$ No & 1 & & & \\
$\quad$ Yes & 2.13 & .008 & 1.13 & 3.72 \\
Dependents & & & & \\
$\quad$ No & 1 & & & \\
$\quad$ Yes & 2.33 & .001 & 1.42 & 3.82 \\
C\&S $R^{2}=.153$ and $N^{c} R^{2}=.207$ & & & & \\
Block 2 significant predictors & & & & \\
Family/friends financial help & & & & \\
$\quad$ No & 1 & & & \\
$\quad$ Yes & 2.01 & .035 & 1.05 & 3.87 \\
Savings & & & & \\
$\quad$ Yes, not used & 1 & & & \\
$\quad$ No & 3.90 & .000 & 2.06 & 7.37 \\
$\quad$ Yes, and used & 5.26 & .000 & 2.91 & 9.51 \\
C\&S $R^{2}$ change $=.090$ and & & & & \\
$N$ & & & & \\
\hline
\end{tabular}

${ }^{a}$ Model is adjusted for age and employment status, which were not significant in multivariate analysis. Overall model Cox and Snell $R^{2}$ : .243; Nagelkerke $R^{2}$ : .329; Hosmer and Lemeshow test: .473; overall model significance: $P=<.001$.

${ }^{\mathrm{b}}$ Cox and Snell.

${ }^{\mathrm{c}}$ Nagelkerke.

life, ${ }^{20}$ cancer treatment, ${ }^{11,23}$ and early mortality ${ }^{24}$ are only slowly coming to light but are likely to be a key concern in the future. ${ }^{18}$

Our findings parallel US findings where $38 \%$ of colorectal cancer survivors indicated at least one financial coping strategy. ${ }^{6}$ Similarities existed in the proportion of survivors borrowing money from family/ friends (15.9\% in our study vs $16.5 \%$ ) and those who withdrew money from savings accounts (34.5\% vs $29.9 \%$ ). However, the percentage incurring debt in the United States was considerably larger $(7.0 \%$ vs 21.8\%). Findings from 2 further US studies ${ }^{7,25}$ indicated between $31 \%$ and $40 \%$ of colorectal cancer survivors used their savings post diagnosis and between $11 \%$ and $18 \%$ borrowed money or took out a loan. Therefore, despite the differences in health care systems, parallels in financial coping strategies arise.

\section{2 | Relevance of objective stress and subjective strain in a mixed public/private health system}

In our study, two-fifths of colorectal cancer survivors reported both cancer-related financial objective stress and subjective strain following diagnosis, similar to a review of US studies. ${ }^{3}$ Previous studies have noted the importance of distinguishing between objective and subjective measures of financial burden. ${ }^{13,18-21}$ Objective stress measures financial hardship on a household basis in terms of illness-related costs. The actual experience of this will depend on a range of factors including the household's income and level of accumulated wealth, financial commitments, and expenditure outgoings, ${ }^{18}$ hence our inclusion here of a question on the household's ability to make ends meet rather than a cost-based measure.

Financial subjective strain adds an extra layer of burden to that experienced by the household and has the potential to impact on emotional strain, in addition to becoming a barrier to care beyond that posed by financial objective stress. ${ }^{13}$ Subjective strain may be particularly important in mixed public-private health systems where access to care is universal. In the case of a private health system, financial objective stress may mean a patient cannot afford to purchase treatment or continue to adhere to treatment. In a mixed health system, the potential effect of subjective strain may be greater as this is linked to psychological distress ${ }^{26}$ and a greater likelihood of cost-related nonadherence to health regimes, ${ }^{27}$ rather than forgoing or not attending treatment due to cost. A holistic appreciation of survivor financial hardship therefore becomes pertinent in a mixed public health care system.

\section{3 | Predictors of objective stress and subjective strain}

Asset depletion was significantly associated with both objective stress and subjective strain. This makes intuitive sense as savings can constitute an important financial buffer for individuals allowing them to compensate for cyclical periods of low income/high expenditure over time, and their depletion implies that survivor's current income levels do not suffice to cover the increased cancer-related expenses post diagnosis. This is in spite of the fact that health care is publicly provisioned in Ireland and that those with medical cards incur minimal direct medical costs and those without (and/or with private health insurance) generally incur modest co-payments.

Both forms of debt accrual, formal and informal, were associated with a greater likelihood of higher objective stress implying that the material level of financial hardship is not sensitive to the source of debt accumulation. This contrasts with subjective strain, where the source of debt appears an important factor in acting as a financial stressor. Only financial help from family members or friends appeared as a significant stressor of subjective strain. Sourcing debt formally was not significantly associated with the increased likelihood of subjective strain and may suggest that survivors feel a greater burden when family members and friends provide financial aid. A formal loan, while an important stressor for objective stress, may be "distant" and more easily placed out of the survivor's mind eliciting less of an emotional response and therefore not impact on survivor subjective strain to the same degree, as discussed by Francoeur. ${ }^{13}$ Furthermore, asking family members for financial help may be difficult for survivors to do, as this requires survivors to openly admit to those closest to them that they need support.

Similarly, while the presence of dependents did not impact on objective stress, they were shown to heighten subjective strain. Intuitively, this makes sense, as feelings of concern about financial situation would be more commonly reported in those with dependents, because they have others to worry about in addition to themselves (and their spouse/partner).

The presence of a stoma in colorectal cancer survivors is associated with decreased patient well-being, poorer social activity, and 
higher levels of depression. ${ }^{28}$ Our study also indicated that having a stoma was associated with increased likelihood of objective stress and subjective strain. This is understandable given the nature of the recurring costs that arise because of a stoma such as the recurring purchase of bags and related accessories ${ }^{29}$ and which can act as an ongoing material drain on finances triggering repeated cost reminders for survivors.

\subsection{Clinical and policy care implications and future research}

As the costs associated with cancer treatment and follow up continue to grow, it is important to gather evidence on the level of financial hardship on cancer survivors across disparate health care systems. Our results are specific to a mixed public-private health care system (albeit one in which everyone is entitled to access care through the public system) and expand the evidence base outside of mainly private health systems.

From the perspective of objective financial stress, a range of potential financial supports are available in Ireland for cancer patients (summary at https://www.cancer.ie/support/coping-with-cancer/ managing-money) ranging from medical cards that entitle individuals to free medical care to tax relief and threshold caps on medicine expenses. Cancer patients, however, are not automatically entitled to a medical card and must apply on a case-by-case basis. Most welfare-based entitlements, including the medical card, are means tested with varying age dependent income thresholds. Medical cards can sometimes be issued on "hardship grounds," but guidelines underpinning this are vague. Therefore, upon diagnosis, cancer patients must (1) investigate the range of financial aid options available and (2) apply for each separately providing financial information for means testing. This can constitute a formidable barrier at a time of elevated stress, anxiety, and worry. ${ }^{3}$ Cancer-related subjective financial strain evidenced in this study has the potential to exacerbate the negative cognitive impact of a cancer diagnosis and further impede the process of applying for financial aid. Recent evidence based on behavioural informed interventions suggests that automatic enrolment ${ }^{30}$ can help to overcome such barriers. The process could be designed to automatically initiate the process of financial aid application upon diagnosis, and where possible, an individual's financial information could be filled in based on revenue records reducing the onus on the patient to proactively investigate the options available and complete the application process.

Our findings also suggest that subjective financial strain is associated with patients receiving loans from family and friends, but not with formal loans. This implies that options to access funds on a formal basis provided from publicly funded schemes at low rates of interest may result in reduced subjective financial strain. Currently, this option is not available to patients. In addition, the difference in associated survivor characteristics between objective stress and subjective strain, such as dependents increasing the risk of subjective strain only, may aid development of separate screening tools to identify those at risk of separate aspects of financial hardship and therefore inform focused interventions rather than general interventions for both. Our evidence therefore supports a multidimensional integrated approach to cancer- related financial interventions making "financial health" assessment a routine part of clinical assessment. ${ }^{31}$

Future research should seek to establish the impact of subjective financial strain on treatment nonadherence and forgetting to take medicine, over and above that induced by material financial costs. This work should be undertaken across disparate health systems as the impact could vary by setting. The distinct pathways by which financial objective stress and strain impact on patient health-related quality of life and mental well-being also offer scope for future research.

\section{5 | Study limitations}

While our participants were recruited from a population-based sampling frame, the patient survey response rate of $39 \%$ is a potential weakness. This is somewhat lower than similar population-based surveys of cancer patients in Ireland $\left(54 \%^{18}\right.$ and $\left.54 \%^{32}\right)$. However, responders in our study were similar to nonresponders across key variables (as outlined previously) providing confidence in the representativeness of our results. Respondents were 1.8 years post diagnosis at the time of questionnaire completion on average, with the vast majority (85\%) less than 2 years post diagnosis. We cannot exclude, however, some measure of recall bias in our results. Our measures of objective stress and subjective strain have not been formally validated, which is a potential weakness. Additional coping strategies, over and above those included in the study exist including selling property to pay for care, reduction of expenditure on basic needs or medicine. ${ }^{3,21}$ The lack of an income measure for respondents is a further limitation, and the addition of information of current employment status among survivors in addition to employment status at diagnosis could have improved the explanatory power of our models.

\section{5 | CONCLUSION}

A notable proportion of colorectal cancer survivors in Ireland suffer cancer-related financial objective stress or subjective strain despite the publicly funded universal access health care setting. Among the key variables associated with this financial hardship are asset depletion and debt accumulation, which impact variably on the objective and subjective hardship. These findings suggest that cancer-related financial hardship and having to use financial coping strategies are not specific to privately funded health care systems.

\section{ACKNOWLEDGEMENTS}

We would like to thank the men and women who took part in this study and the health professionals who helped screen potential participants for eligibility.

Funding for this study was supplied by the Irish Health Research Board (SA/2004/1) and the work received no specific grant from any funding agency in the commercial or not-for-profit sectors. The funders had no role in the conduct of the research, determining the content of the paper, or writing of the manuscript.

\section{CONFLICT OF INTEREST}

The authors have no conflicts of interest. 


\section{ORCID}

Paul Hanly (iD http://orcid.org/0000-0002-5348-4825

Rebecca Maguire (iD) http://orcid.org/0000-0002-0368-4626

Linda Sharp (D) http://orcid.org/0000-0001-9515-1722

\section{REFERENCES}

1. Ó Céilleachair A, Hanly P, Skally M, et al. Counting the cost of cancer: out-of-pocket payments made by colorectal cancer survivors. Support Care Cancer. 2017;25(9):2733-2741.

2. Zajacova A, Dowd JB, Schoeni RF, Wallace RB. Employment and income losses among cancer survivors: estimates from a national longitudinal survey of American families. Cancer. 2015;121(24):4425-4432.

3. Altice CK, Banegas MP, Tucker-Seeley RD, Yabroff KR. Financial hardships experienced by cancer survivors: a systematic review. J Nat Cancer Inst. 2016;109(2). pii: djw205, https://doi.org/10.1093/jnci/ djw205

4. Meneses K, Azuero A, Hassey L, McNees P, Pisu M. Does economic burden influence quality of life in breast cancer survivors? Gynecol Oncol. 2012;124(3):437-443.

5. Jagsi R, Pottow JA, Griffith KA, et al. Long-term financial burden of breast cancer: experiences of a diverse cohort of survivors identified through population-based registries. J Clin Oncol. 2014;32(12): 1269-1276.

6. Shankaran V, Jolly S, Blough D, Ramsey SD. Risk factors for financial hardship in patients receiving adjuvant chemotherapy for colon cancer: a population-based exploratory analysis. J Clin Oncol. 2012;30(14): 1608-1614.

7. Veenstra CM, Regenbogen SE, Hawley ST, et al. A composite measure of personal financial burden among patients with stage III colorectal cancer. Med Care. 2014;52(11):957-962.

8. Ramsey S, Blough D, Kirchhoff A, et al. Washington State cancer patients found to be at greater risk for bankruptcy than people without a cancer diagnosis. Health Aff (Millwood). 32(6):1143-1152.

9. Banegas MP, Guy GP Jr, de Moor JS, et al. For working-age cancer survivors, medical debt and bankruptcy create financial hardships. Health Aff (Millwood). 2016;35(1):54-61.

10. $\mathrm{Y} 1 \mathrm{~K}$, Morozumi $\mathrm{R}$, Matsumura $\mathrm{T}$, et al. Increased financial burden among patients with chronic myelogenous leukaemia receiving imatinib in Japan: a retrospective survey. BMC Cancer. 2012;12:152.

11. Zheng Z, Han X, Guy GP Jr, et al. Do cancer survivors change their prescription drug use for financial reasons? Findings from a nationally representative sample in the United States. Cancer. 2017;123(8): 1453-1463.

12. Ferlay J, Shin HR, Bray F, Forman D, Mathers C, Parkin DM. Estimates of worldwide burden of cancer in 2008: GLOBOCAN 2008. Int J Cancer. 2010;127(12):2893-2917.

13. Francoeur RB. Cumulative financial stress and strain in palliative radiation outpatients: the role of age and disability. Acta Oncol. 2005;44(4): 369-381.

14. Lipscomb J, Gotay CC, Snyder CF. Patient-reported outcomes in cancer: a review of recent research and policy initiatives. CA Cancer $J$ Clin. 2007;57(5):278-300.

15. Valtorta NK, Hanratty B. Socioeconomic variation in the financial consequences of ill health for older people with chronic diseases: a systematic review. Maturitas. 2013;74(4):313-333.

16. Central Statistics Office. Health Status and Health Service Utilization. Cork: Central Statistics Office; 2011.

17. Céilleachair AÓ, Costello L, Finn C, et al. Inter-relationships between the economic and emotional consequences of colorectal cancer for patients and their families: a qualitative study. BMC Gastroenterol. 2012;12(1):62.
18. Sharp L, Carsin AE, Timmons A. Associations between cancer-related financial stress and strain and psychological well-being among individuals living with cancer. Psychooncology. 2013;22(4):745-755.

19. Sharp L, Timmons A. Pre-diagnosis employment status and financial circumstances predict cancer-related financial stress and strain among breast and prostate cancer survivors. Support Care Cancer. 2016;24:599-709.

20. Sharp L, O'Leary E, O'Ceilleachair A, Skally M, Hanly P. Financial impact of colorectal cancer and its consequences: associations between cancer-related financial stress and strain and health-related quality of life. Dis Colon Rectum. 2018;61(1):27-35.

21. Azzani M, Roslani AC, Su TT. The perceived cancer-related financial hardship among patients and their families: a systematic review. Support Care Cancer. 2015;23(3):889-898.

22. Yabroff KR, Dowling EC, Guy GP Jr, et al. Financial hardship associated with cancer in the United States: Findings from a population-based sample of adult cancer survivors. J Clin Oncol. 2016;34(3):259-267.

23. Kent EE, Forsythe LP, Yabroff KR, et al. Are survivors who report cancer-related financial problems more likely to forgo or delay medical care? Cancer. 2013;119(20):3710-3717.

24. Ramsey SD, Bansal A, Fedorenko CR, et al. Financial insolvency as a risk factor for early mortality among patients with cancer. J Clin Oncol. 2016;34(9):980-986.

25. Regenbogen SE, Veenstra CM, Hawley ST, et al. The personal financial burden of complications after colorectal cancer surgery. Cancer. 2014;120(19):3074-3081.

26. Sun F, Hilgeman M, Durkin DW, Allen RS, Burgio LD. Perceived income inadequacy as a predictor of psychological distress in Alzheimer's caregivers. Psychol Aging. 2009;24(1):177-183.

27. Patel MR, Kruger DJ, Cupal S, Zimmerman MA. Effect of financial stress and positive financial behaviors on cost-related nonadherence to health regimens among adults in a community-based setting. Prev Chronic Dis. 2016;13:E46.

28. Cotrim H, Pereira G. Impact of colorectal cancer on patient and family: implications for care. Eur J Oncol Nurs. 2008;12(3):217-226.

29. Macafee DA, West J, Scholefield JH, Whynes DK. Hospital costs of colorectal cancer care. Clin Med Oncol. 2009;3:27-37.

30. Costa E, Giardini A, Savin M, et al. Interventional tools to improve medication adherence: review of literature. Patient Prefer Adherence. 2015;14(9):1303-1314.

31. Shankaran V, Ramsey S. Addressing the financial burden of cancer treatment: from copay to can't pay. JAMA Oncol. 2015;1(3):273-274.

32. Drummond FJ, Kinnear H, O'Leary E, Donnelly GA, Sharp L. Long-term health-related quality of life of prostate cancer survivors varies by primary treatment. Results from the PiCTure (Prostate Cancer Treatment, your experience) study. J Cancer Surviv. 2015;9(2):361-372.

\section{SUPPORTING INFORMATION}

Additional supporting information may be found online in the Supporting Information section at the end of the article.

How to cite this article: Hanly P, Maguire R, Ceilleachair AO, Sharp L. Financial hardship associated with colorectal cancer survivorship: The role of asset depletion and debt accumulation. Psycho-Oncology. 2018;27:2165-2171. https://doi.org/ 10.1002/pon.4786 